\title{
Investigation of Performance of Glass Fibre Impregnated with Bitumen Emulsion against Reflective Cracking \\ Ogundipe Olumide Moses*
}

Civil Engineering Department, Ekiti State University, Ado-Ekiti, Nigeria

\begin{abstract}
The study investigates the use of glass fibre impregnated with bitumen emulsion with $6 \mathrm{~mm}$ aggregates compacted on it as a Stress Absorbing Membrane Interlayer (SAMI) to retard reflective cracking. The causes and mechanism of reflective cracking in an overlay over a cracked pavement were highlighted. Tests were carried out in a wheel tracking facility to induce modes I and II cracking. The effects of temperature, load level, composition of SAMI and overlay thickness on the performance of the SAMls were evaluated. It was found that the two SAMls investigated in this study were both able to retard reflective cracking. Better relative performance was observed with low overlay thickness and at high load level. Also, the study showed that temperature influenced the performance of the SAMIs and indicated that difference in the viscosity of the bitumen emulsion used in the SAMIs led to difference in performance. It was observed that the interface shear strain of the overlay-SAMI interface influenced the performance of the SAMI.
\end{abstract}

Keywords: Cracks; Overlay; Interlayer; Temperature; Load level

\section{Introduction}

The method commonly used to rehabilitate deteriorated pavements is by overlaying with a new surfacing material. Cleveland et al. [1] stated that for both flexible and composite pavements, a common technique used by many agencies for preventive maintenance and/or rehabilitation was simply to construct thin Hot Mix Asphalt (HMA) overlay, normally between 25 and $50 \mathrm{~mm}$ thick. Overlaying cracked pavements prevents water from infiltrating through the cracks into the pavement structure, thus preventing the deterioration of the pavement structure and increasing its structural capacity. Also, it reduces roughness, restores skid resistance, and improves the overall ride quality to the travelling public. However, it has been found that the cracks propagate through the overlay to its surface, a phenomenon called reflective cracking.

Reflective cracking can be defined simply as the propagation of existing cracks in an old pavement through the underside of the overlay to the surface. (Figure 1) shows a schematic of reflective cracking in HMA overlay on Portland Cement Concrete (PCC) slab or Asphalt Concrete (AC). Reflective cracking is often initiated at the bottom of the overlay material and grows until it appears at the surface. Also top-down cracking (cracks initiating at the surface and growing into the lower layers) occurs especially where there are large temperature variations in the pavement (thermal cracking).

A number of factors have been identified as the causes of reflective cracking. Palacios et al. [2] reported that cracks propagate to new overlays due to vertical movement of the underlying pavement layer which may be due to traffic loading, frost heave and consolidation of the sub grade soils and/or the horizontal movement of the pavement upper layers due to temperature changes. Quintus et al. [3] reported three causes of reflective cracking, the major being horizontal movements

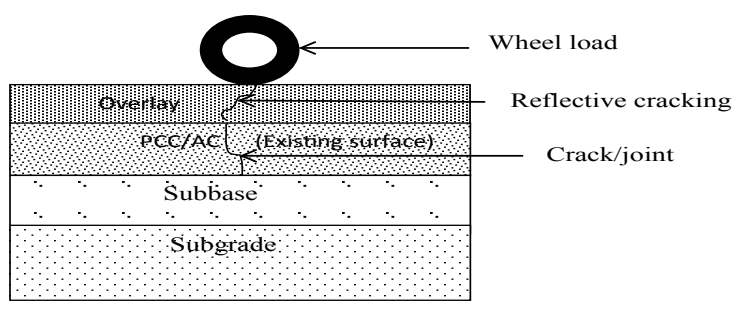

Figure 1: Schematic of reflective cracking in pavement. from the expansion and contraction of the base pavement that is caused by temperature changes; the differential vertical deflections between the approach and departure slabs or across transverse cracks, which create shear stresses; and the curling of PCC slabs during colder temperature when the HMA overlay is stiff and brittle.

Abe et al. [4] stated that cracking was caused on the surface of the overlay at an early stage by the movement of the pavement and traffic load. Smith [5] also mentioned the differential vertical movement at a crack or slab joint in the old pavement which induces a vertical shear stress in the overlay, horizontal movement associated with temperature or moisture changes in the old pavement which induces tensile stress in the overlay or live load flexural stress in the overlay, which tends to concentrate directly over discontinuities. Based on the causes identified by researchers, there seems to be an agreement on the causes of reflective cracking. While it is common knowledge that factors such as sub grade conditions, pavement material quality, workmanship etc affect the performance of a pavement; the principal factors responsible for reflective cracking are the action of traffic loading on an overlay on a cracked pavement and thermal stresses developed as a result of daily/seasonal temperature variation. This study has concentrated on reflective cracking caused by the action of traffic loading.

It is important that the mechanisms of reflective cracking are well understood to be able to provide a solution to the problem. This is illustrated in Figures 2 and 3. Figure 2a depicts a situation where the moving wheel on the edge of the pavement above the crack produces maximum shear stresses, A and C respectively as shown in Figure 3, while in Figure 2b, the wheel directly on the overlay above the cracked pavement generates flexural stresses producing maximum bending stress, B as indicated in Figure 3. This illustration indicates two of the three modes of reflective cracking - Modes I and II. Molenaar [6]

*Corresponding author: Ogundipe Olumide Moses, Civil Engineering Department, Ekiti State University, Ado-Ekiti, Nigeria, Tel: +2348107825001; E mail: momide2002@yahoo.com

Received November 11, 2013; Accepted January 21, 2014; Published January 30, 2014

Citation: Moses OO (2014) Investigation of Performance of Glass Fibre Impregnated with Bitumen Emulsion against Reflective Cracking. J Civil Environ Eng 4: 137. doi:10.4172/2165-784X.1000137

Copyright: (C) 2014 Moses OO. This is an open-access article distributed under the terms of the Creative Commons Attribution License, which permits unrestricted use, distribution, and reproduction in any medium, provided the original author and source are credited. 
Citation: Moses OO (2014) Investigation of Performance of Glass Fibre Impregnated with Bitumen Emulsion against Reflective Cracking. J Civil Environ Eng 4: 137. doi:10.4172/2165-784X.1000137

Page 2 of 6

established the three modes: mode I, mode II and mode III cracking. Mode I cracking occur due to tensile stresses caused by a drop in temperature or flexure under traffic loading. Mode II cracking is caused by the effects of shear stress induced by a loaded wheel crossing from one side of a transverse crack or joint to the other. Mode III, referred to as the tearing mode, is less common. This occurs in pavements when the wheel load travels along (parallel to) a crack. Figure 4 shows the three modes of cracking.

A number of measures have been adopted by engineers with the aim of retarding reflective cracking in overlays and results achieved have been mixed. These measures include: thick overlays, overlay mixture modification, overlay reinforcement, stress or strain absorbing interlayer's and reinforcing interlayer's. Al-Qadi et al. [7] stated that various interlayer materials namely: geosynthetics, geocomposites, steel reinforcement netting, and modified HMA, have been used as interlayer systems for the purpose of reducing reflective cracking, and that their effectiveness is still not well quantified due to lack of understanding of the reflective cracking mechanism and because imperfect evaluation approaches are used. No current pavement rehabilitation techniques have been shown to solve completely the problem of reflective cracking. This has been attributed to the number of variables that are involved in reflective cracking [8].

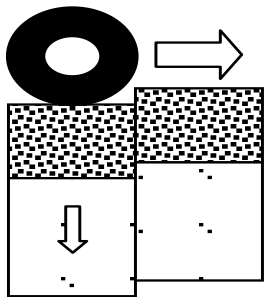

(a)

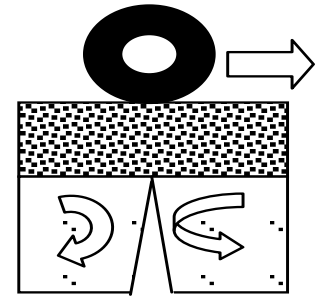

(b)
Figure 2: Movements in pavement joints and cracks.

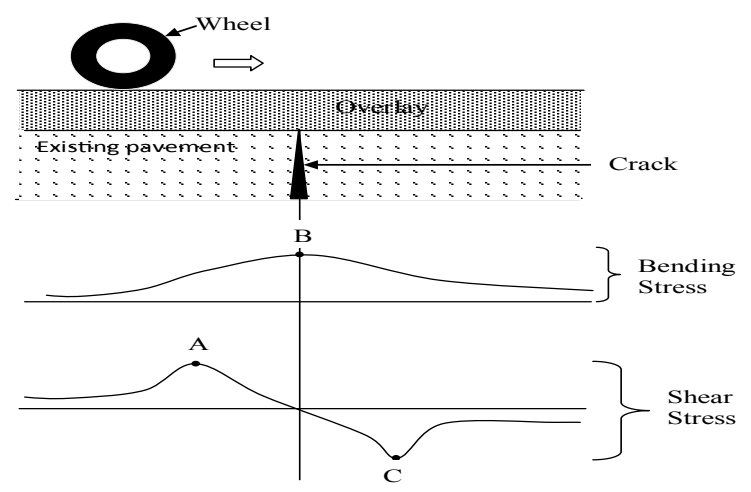

Figure 3: Stresses induced by wheel load (Adapted after Lytton, [7]).

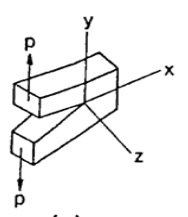

(a)

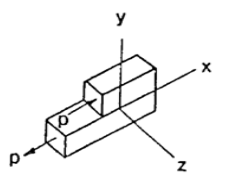

(b)

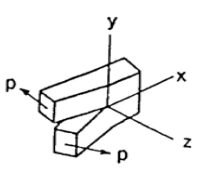

(c)
Figure 4: Modes of cracking (a) mode I (b) mode II and (c) mode III.

\begin{tabular}{|l|c|}
\hline Sample type & Percent by composition of aggregate \\
\hline $10 \mathrm{~mm}$ aggregate & $37 \%$ \\
\hline $6 \mathrm{~mm}$ aggregate & $26 \%$ \\
\hline Dust & $36 \%$ \\
\hline Filler & $1 \%$ \\
\hline Binder type & $10 / 20,40 / 60$ bitumen \\
\hline Binder content & $5.3 \%$ by mass of total mix \\
\hline Target air void & $5 \%$ \\
\hline
\end{tabular}

Table 1: Mix composition for $10 \mathrm{~mm}$ asphalt concrete.

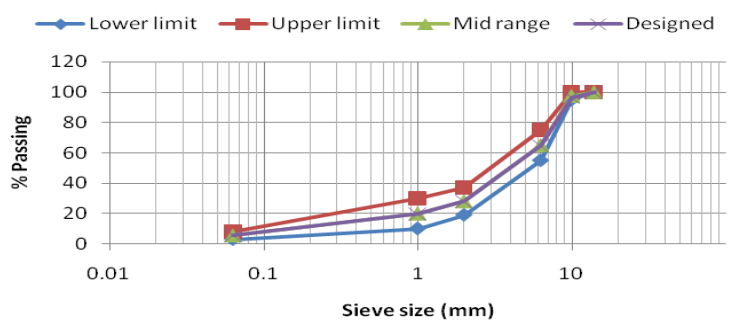

Figure 5: Particle size distribution curve for the blend of aggregates for 10 $\mathrm{mm}$ asphalt concrete.

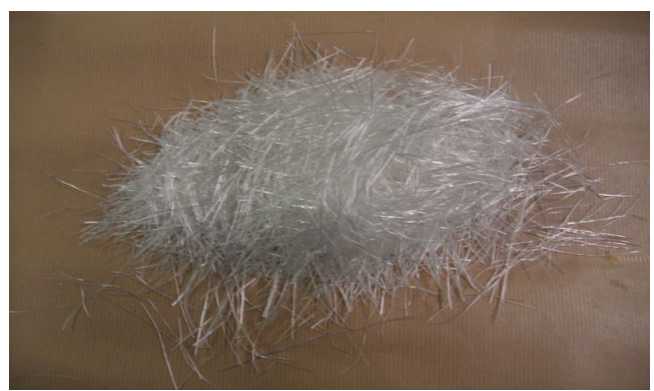

Figure 6: Chopped glass fibres.

This research work aims to evaluate the contribution of a particular type of stress absorbing membrane interlayer (SAMI) designed to deform horizontally or vertically, therefore allowing the movement (vertical/horizontal) of the underlying pavement layers without causing large tensile stresses in the asphalt overlay. The effect of the SAMI on overlaid pavement performance in delaying reflective cracking and the influence of certain variables such as temperature overlay thickness, and load levels have all been studied.

\section{Materials and Methods}

\section{Materials}

The materials used in this study were as follows:

- $10 \mathrm{~mm}$ asphaltic concrete with $10 / 20$ or $40 / 60$ penetration grade bitumen. The mix composition is as shown in Table 1 and the particle size distribution curve for the blend of aggregates is shown in Figure 5.

- Proprietary SAMIs designated as SAMI 1 and SAMI 2. SAMI 1 is prepared by sandwiching chopped glass fibre shown in Figure 6 at $120 \mathrm{~g} / \mathrm{m}^{2}$ between layers of ordinary bitumen emulsion at $0.9 \mathrm{~L} / \mathrm{m}^{2}$ with $6 \mathrm{~mm}$ aggregates spread and compacted on top at a rate of $8 \mathrm{~kg} / \mathrm{m}^{2}$, while SAMI 2 varies in its use of polymer modified bitumen emulsion.

- A $10 \mathrm{~mm}$ thick rubber mat of $6.45 \mathrm{MPa}$ stiffness was used to simulate the pavement foundation. 


\begin{tabular}{|l|c|c|c|}
\hline \multirow{2}{*}{ Asphalt concrete (AC) } & \multicolumn{3}{|c|}{ Stiffness (MPa) } \\
\cline { 2 - 4 } & $10^{\circ} \mathrm{C}$ & $20^{\circ} \mathrm{C}$ & $30^{\circ} \mathrm{C}$ \\
\cline { 2 - 4 } & 10000 & 3900 & 1100 \\
\hline AC (40/60) & 15400 & 9600 & 5000 \\
\hline
\end{tabular}

Table 2: Indirect tensile stiffness moduli.

\begin{tabular}{|l|c|c|c|}
\hline Bitumen emulsion & $\begin{array}{c}\text { Viscosity } \\
\text { (Pa.s) @ 25 } \mathbf{5}^{\circ} \mathbf{C}\end{array}$ & $\begin{array}{c}\text { Viscosity } \\
\text { (Pa.s) @ 30 30 }\end{array}$ & $\begin{array}{c}\text { Viscosity } \\
\text { (Pa.s) @ 40 40 }\end{array}$ \\
\hline Ordinary bitumen emulsion & 0.700 & 0.580 & 0.390 \\
\hline polymer modified bitumen emulsion & 0.184 & 0.194 & 0.180 \\
\hline
\end{tabular}

Table 3: Viscosity of bitumen emulsion.

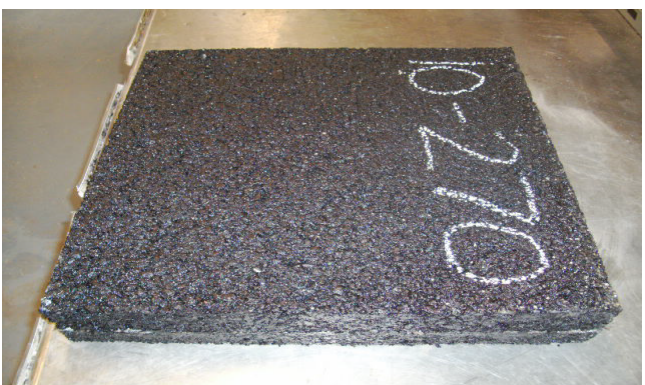

Figure 7: A typical $500 \mathrm{~mm}$ by $500 \mathrm{~mm}$ slab.

- The indirect tensile stiffness moduli (ITSM) of the mixtures were determined using the Nottingham asphalt tester (NAT) in accordance with British standard [9]. In the ITSM a load pulse is applied to the vertical diameter of a cylindrical specimen $(100 \mathrm{~mm}$ in diameter and $40 \mathrm{~mm}$ thick) positioned centrally between the upper and the lower platens and the resultant peak transient deformation along the horizontal diameter is measured. The ITSM results for the $10 \mathrm{~mm}$ asphalt concrete with $10 / 20$ and $40 / 60$ penetration grade bitumen at $10^{\circ} \mathrm{C}, 20^{\circ} \mathrm{C}$ and $30^{\circ} \mathrm{C}$ are shown in Table 2 . The viscosity of the bitumen emulsion is shown in Table 3.

\section{Methods}

Sample preparation: The test specimens were made up of beams of length $404 \mathrm{~mm}$ and width $50 \mathrm{~mm}$. The bottom (base) layer was a $30 \mathrm{~mm}$ thick $10 \mathrm{~mm}$ asphaltic concrete with $10 / 20$ penetration grade bitumen, the middle layer (where present) was SAMI and the top layer (overlay) was a $10 \mathrm{~mm}$ asphaltic concrete with $40 / 60$ penetration grade bitumen.

The beams were obtained by manufacturing a slab of dimension $500 \mathrm{~mm} \times 500 \mathrm{~mm}$ (Figure 7). For the base layer, the aggregates and binder were batched as shown in Table 1 , heated at $185^{\circ} \mathrm{C}$ and compacted in a mould of dimension $500 \mathrm{~mm} \times 500 \mathrm{~mm} \times 205 \mathrm{~mm}$ with a roller compactor at a temperature of $180^{\circ} \mathrm{C}$ to a thickness of $30 \mathrm{~mm}$. The SAMIs were prepared by sandwiching $60 \mathrm{~mm}$ glass fibre strands between layers of bitumen emulsion and $6 \mathrm{~mm}$ aggregates compacted over them. The aggregates for the top layer were batched as shown in Table 1, heated to $160^{\circ} \mathrm{C}$ and compacted to the required thickness at $150^{\circ} \mathrm{C}$. All the mixtures were mixed in accordance with British standard [10] and compacted in accordance with British standard [11].

Ten beams of length $404 \mathrm{~mm}$ and width $50 \mathrm{~mm}$ were cut from each slab and a $10 \mathrm{~mm}$ wide notch was sawn at the centre of the beam through the $30 \mathrm{~mm}$ base layer to simulate the crack. Two aluminium brackets were glued to each side of the split base as LVDT measurement points. Typical beams with $10 \mathrm{~mm}$ notch in the base layer and aluminium brackets attached are shown in Figure 8.
Test procedure: The test was carried out by placing a $10 \mathrm{~mm}$ thick rubber mat on the base of a steel mould on a reciprocating table. The beams were placed in a conditioning cabinet at test temperature for a minimum of five hours. The specimen sides were painted white to allow monitoring of crack growth during the test. The beams were placed in the steel mould on the wheel tracking facility and they were clamped at the top and sides to prevent them moving sideways. The Linear Variable Differential Transformers (LVDTs) were positioned on the aluminium brackets and connected to the data acquisition system. The specimens were trafficked and the numbers of wheel cycles for crack growth to the top of the overlay were recorded. The wheel tracker with a sample in place is shown in Figure 9. The test was carried out at $10^{\circ} \mathrm{C}$, $20^{\circ} \mathrm{C}$ and $30^{\circ} \mathrm{C}$. Two replicates were tested in each case. The test plan is shown in Table 4.

Test results and discussion: The results from the wheel tracking test were processed. Firstly, the number of wheel cycles for crack propagation to failure (crack appearing at the top of the overlay) was recorded for all specimens. The vertical displacements of the specimens during test were obtained from the LVDTs. The results presented are the averages of the replicates.

The specimen names and references used for the presentation of results are shown in Table 5. The results for the numbers of wheel cycles to failure at $10^{\circ} \mathrm{C}, 20^{\circ} \mathrm{C}$ and $30^{\circ} \mathrm{C}$ with a $2.4 \mathrm{kN}$ (approximately 1.1 $\mathrm{MPa}$ ) load applied are shown in Figures 10-12, respectively. Figure 13 shows the results at $30^{\circ} \mathrm{C}$ with a $1.35 \mathrm{kN}$ (approximately $0.6 \mathrm{MPa}$ ) load applied. The figures show both SAMI 1 and SAMI 2 were able to increase the life of the overlay in most cases. Also, it can be seen from

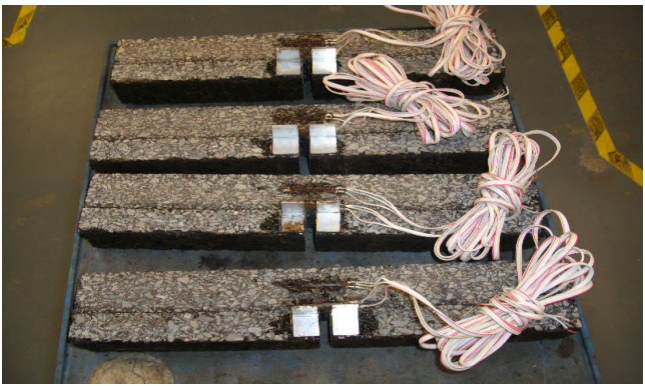

Figure 8: Typical beams with $10 \mathrm{~mm}$ notch and LVDT measurement points

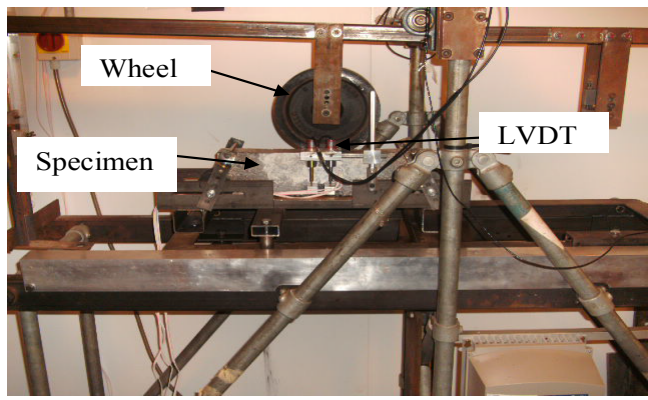

Figure 9: Wheel tracking machine with sample.

\begin{tabular}{|c|c|c|c|c|c|}
\hline \multicolumn{2}{|c|}{ Load $(\mathrm{kN})$} & \multicolumn{3}{c|}{2.4} & 1.35 \\
\hline \multirow{2}{*}{ Base thickness $(\mathrm{mm})$} & Overlay thickness $(\mathrm{mm})$ & 10 & 20 & 30 & 30 \\
\cline { 3 - 6 } & 40 & $\sqrt{ }$ & $\sqrt{ }$ & $\sqrt{ }$ & $\sqrt{ }$ \\
\hline 30 & 60 & $\sqrt{ }$ & $\sqrt{ }$ & $\sqrt{ }$ & $\sqrt{ }$ \\
\hline 30 & \multicolumn{4}{|c}{} \\
\hline \multicolumn{4}{|c|}{ Table 4: Test plan. }
\end{tabular}




\begin{tabular}{|l|c|}
\hline Specimen name & Specimen reference \\
\hline $40 \mathrm{~mm}$ Overlay (Control) & O40 \\
\hline SAMI 1 with $40 \mathrm{~mm}$ Overlay & SA1O40 \\
\hline SAMI 2 with $40 \mathrm{~mm}$ Overlay & SA2O40 \\
\hline $60 \mathrm{~mm}$ Overlay (Control) & O60 \\
\hline SAMI 1 with $60 \mathrm{~mm}$ Overlay & SA1060 \\
\hline SAMI 2 with $60 \mathrm{~mm}$ Overlay & SA2O60 \\
\hline
\end{tabular}

Table 5: Specimen names and references.

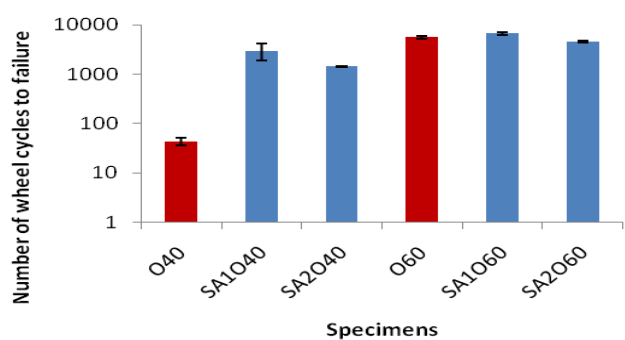

Figure 10: Number of wheel cycles to failure at $10^{\circ} \mathrm{C}$ with a $2.4 \mathrm{kN}$ load applied

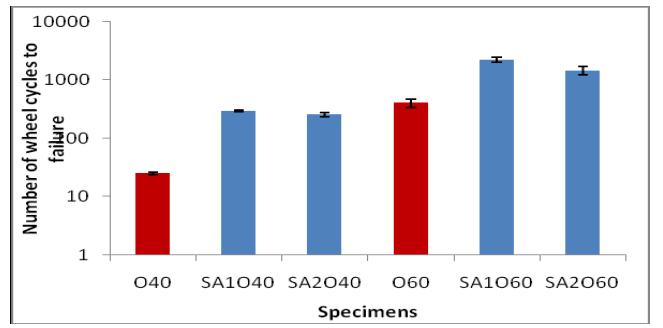

Figure 11: Number of wheel cycles to failure at $20^{\circ} \mathrm{C}$ with a $2.4 \mathrm{kN}$ load applied

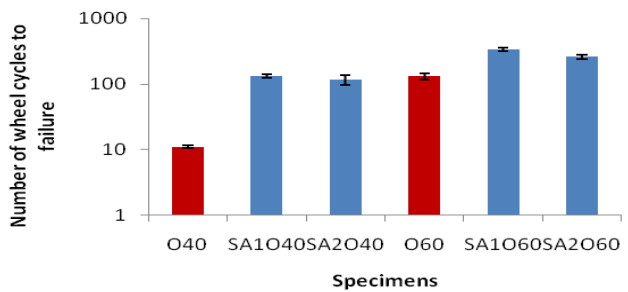

Figure 12: Number of wheel cycles to failure at $30^{\circ} \mathrm{C}$ with a $2.4 \mathrm{kN}$ load applied.

the figures that the specimens with SAMI 1 gave better performance than those with SAMI 2. This may be because the bitumen emulsion used in SAMI 2 was of insufficient viscosity, although the exact reason why this should give reduced performance is unclear.

Effect of load levels: Two load levels were used at $30^{\circ} \mathrm{C}: 2.4 \mathrm{kN}$ $(1.1 \mathrm{MPa})$ and $1.35 \mathrm{kN}(0.6 \mathrm{MPa})$. The former is representative of tyre pressures on airfields and the latter representative of tyre pressures on highways. The numbers of wheel cycles to failure were normalized against the respective control specimens of equivalent thickness. The results as shown in (Figure 14) indicate that the contribution of the SAMIs in resisting reflective cracking was more pronounced in specimens tested under a load of $2.4 \mathrm{kN}(1.1 \mathrm{MPa})$ than under $1.35 \mathrm{kN}$ $(0.6 \mathrm{MPa})$, in most cases.

The reason for the better relative performance under a load of 2.4 $\mathrm{kN}$ compared to $1.35 \mathrm{kN}$ may be because of the permanent deformation associated with creep at high temperature. Further studies are to be carried out to evaluate the effect of load level at $10^{\circ} \mathrm{C}$ and $20^{\circ} \mathrm{C}$.
Effect of temperature: The effect of temperature on the performance of SAMI 1 and SAMI 2 against reflective cracking was considered by carrying out tests at $10^{\circ} \mathrm{C}, 20^{\circ} \mathrm{C}$ and $30^{\circ} \mathrm{C}$ with a $2.4 \mathrm{kN}$ $(1.1 \mathrm{MPa})$ load applied. The results presented in Figure 15 show the number of wheel cycles to failure for the specimens with SAMIs as ratio of those without SAMIs (control). It can be seen from the figure that when an overlay of $40 \mathrm{~mm}$ thick was used, the life to failure as ratio of control decreases with increase in temperature, which may be related to change in stiffness of the overlay (Table 2) and SAMI with temperature and the reduction in the stiffness of the overlay-SAMI interface as temperature increases [12]. Also, the figure shows that when an overlay of $60 \mathrm{~mm}$ was used, the best performance was recorded at $20^{\circ} \mathrm{C}$, while the worst performance was observed at $10^{\circ} \mathrm{C}$. The reason for this is probably because the overlay becomes brittle due to long exposure to cold temperature $\left(10^{\circ} \mathrm{C}\right)$, while it becomes susceptible to permanent deformation at $30^{\circ} \mathrm{C}$.

Effect of overlay thickness: The effect of overlay thickness on the performance of the SAMIs was considered by using two different overlay thicknesses of $40 \mathrm{~mm}$ and $60 \mathrm{~mm}$ for specimens with SAMI 1 and SAMI 2. The results were normalized by dividing the number of cycles to failure of the test specimens by the number of wheel cycles to failure for control specimens of equivalent overall thickness. The results are shown in Figures 16-19.

The figures show that specimens with SAMIs gave better performance against the offset of crack when a $40 \mathrm{~mm}$ overlay was

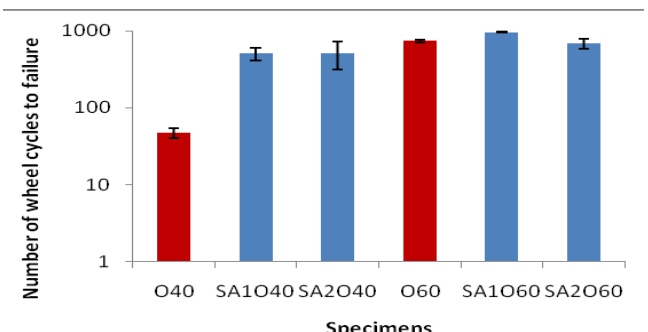

Figure 13: Number of wheel cycles to failure at $30^{\circ} \mathrm{C}$ with a $1.35 \mathrm{kN}$ load applied.

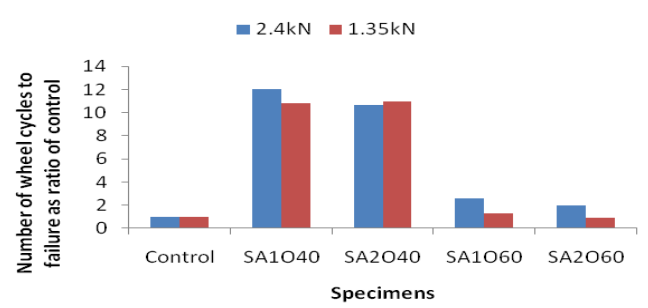

Figure 14: Number of wheel cycles to failure as a ratio of control with $2.4 \mathrm{kN}$ and $1.35 \mathrm{kN}$ loads applied at $30^{\circ} \mathrm{C}$.

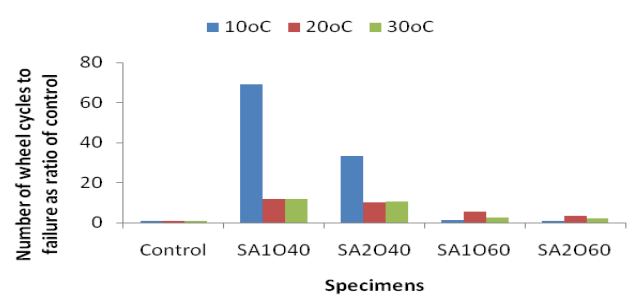

Figure 15: Number of wheel cycles to failure as a ratio of control with a $2.4 \mathrm{kN}$ load applied at $10^{\circ} \mathrm{C}, 20^{\circ} \mathrm{C}$ and $30^{\circ} \mathrm{C}$. 
used than a $60 \mathrm{~mm}$ overlay. This indicates that the SAMIs provide better resistance to the offset of crack with a lower overlay thickness. Molenaar et al. [13] found that when SAMIs are used against reflective cracking, a thin overlay would have a longer life than a thick overlay. The reason for the better performance of thinner overlay over a SAMI on a cracked pavement is probably because the SAMI becomes ineffective once crack is initiated at the bottom of the overlay. While it may take greater number of wheel load cycles for the cracks to propagate to the surface when thicker overlay is used, the additional cost of the overlay may outweigh the life gained. Therefore, having thinner overlay over a SAMI provides a better relative benefit than thicker overlay.

Displacement: The initial absolute displacements of the cracked base layer of the specimens are shown in Figure 20. It can be seen that the vertical movement of the specimens increases with increasing temperature. Also the figure shows that lower absolute displacements were measured in the control specimens than in those with SAMIs. This

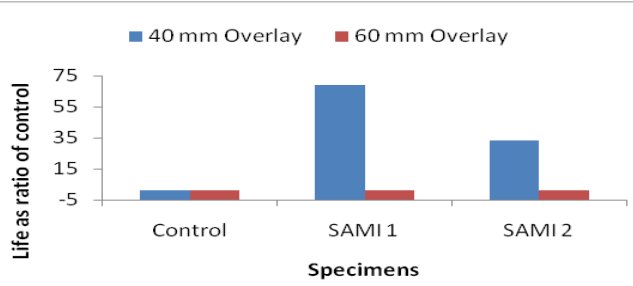

Figure 16: The number of wheel cycles to failure as a ratio of control for specimens with $40 \mathrm{~mm}$ and $60 \mathrm{~mm}$ overlays and a $2.4 \mathrm{kN}$ load applied at $10^{\circ} \mathrm{C}$

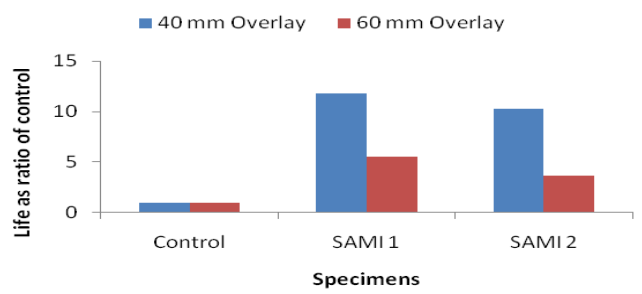

Figure 17: The number of wheel cycles to failure as ratio of control for specimens with $40 \mathrm{~mm}$ and $60 \mathrm{~mm}$ overlays and a $2.4 \mathrm{kN}$ load applied at $20^{\circ} \mathrm{C}$

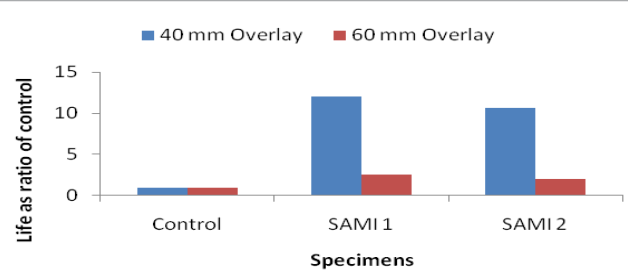

Figure 18: The number of wheel cycles to failure as ratio of control for specimens with $40 \mathrm{~mm}$ and $60 \mathrm{~mm}$ overlays and a $2.4 \mathrm{kNload}$ applied at $30^{\circ} \mathrm{C}$.

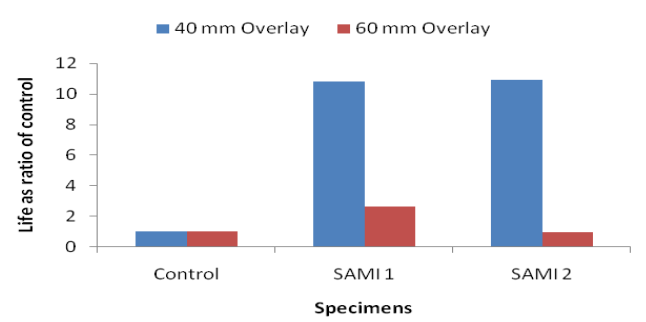

Figure 19: The number of wheel cycles to failure as ratio of control for specimens with $40 \mathrm{~mm}$ and $60 \mathrm{~mm}$ overlays and a $1.35 \mathrm{kN}$ load applied at $30^{\circ} \mathrm{C}$.

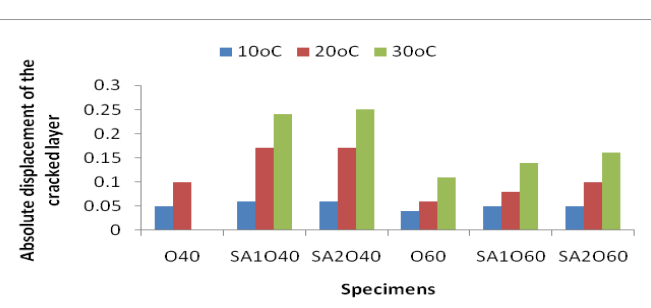

Figure 20: Initial absolute displacement of the specimens under a $2.4 \mathrm{kN}$ load at $10^{\circ} \mathrm{C}, 20^{\circ} \mathrm{C}$ and $30^{\circ} \mathrm{C}$

shows that the increased deflection of the specimen that accompanies the use of the SAMIs does not have a detrimental effect on their performance. The shear strain at the overlay-SAMI interface isolates the overlay from the strain concentration immediately above the base.

\section{Conclusion}

This study has shown that the SAMIs evaluated (comprising chopped glass fibre, bitumen emulsion and single-sized aggregate) are able to delay the appearance of cracks in an overlay over a cracked pavement. The degree of improvement varied up to a factor of 69 for thin $40 \mathrm{~mm}$ overlay at $10^{\circ} \mathrm{C}$. It was discovered that SAMI 1 gave better performance against reflective cracking than SAMI 2, which may be due to the viscosity of the bitumen emulsion used in the SAMIs.

In general, it was found that the SAMIs gave better relative performance when a higher load level was adopted for the trafficking of the specimens. It was also found that the relative benefit of the SAMIs decreased as the overlay thickness increased. This is possibly because the SAMIs become less effective once a crack has been initiated in the overlay. Furthermore, the test results showed that temperature influences the performance of the SAMIs, but in a complex way. The shear strain at the overlay-SAMI interface plays a role in isolating the overlay from strain concentration around the crack region, therefore increasing the life to failure of the overlay. Large scale testing is to be carried out to evaluate the practical/field significance of the study. Also, the use of different types of binder with the glass fibre and modelling of the test are to be considered in future study.

\section{References}

1. Cleveland GS, Button JW, Lytton RL (2002) Geosynthetic in flexible and rigid pavement overlay systems to reduce reflection cracking. Texas Transport Institute, Texas A\&M University System. Report 1777-1.

2. Palacios C, Chehab GR, Chaignon F, Thompson M (2008) Evaluation of fiber reinforced bituminous interlayer's for pavement preservation. Proc. $6^{\text {th }}$ International RILEM Conference.

3. Von Quintus HL, Mallela J, Weiss W, Shen S (2009) Techniques for mitigation of reflective cracking. Applied Research Associates, Champaign, IL, Interim Report AAPTP 05-04.

4. Abe N, Maehara H, Maruyama T, Ooba K (2000) An examination of factor which affects reflective cracking. Proc. $4^{\text {th }}$ International RILEM Conf.

5. Smith (1983) Laboratory testing of fabric interlayer's for asphalt concrete paving, Transportation Research Record 916, 6-17.

6. Moleenar AAA (1993) Evaluation of pavement structure with emphasis on reflective cracking, Proc. $2^{\text {nd }}$ International RILEM Conf.

7. Al-Qadi IL, Baek J, Buttlar WG, (2008) Development of reflective cracking index to determine the effectiveness and service life of strip interlayer systems. Proc. $6^{\text {th }}$ International RILEM Conf

8. Bhosale SS and Mandal JN, (2008) Open graded asphalt concrete for mitigation of reflection cracking on asphalt concrete overlays, Proc. $12^{\text {th }}$ International Conference of International Association for Computer Methods and Advances in Geomechanics (IACMAG).

9. BSI (1993) Method for determination of the indirect tensile stiffness modulus of bituminous mixture. British Standard Institution, London, DD 213. 
Citation: Moses OO (2014) Investigation of Performance of Glass Fibre Impregnated with Bitumen Emulsion against Reflective Cracking. J Civil Environ Eng 4: 137. doi:10.4172/2165-784X.1000137

10. BSI (2004) Bituminous mixtures-test method for hot mix asphalt: Laboratory mixing. British Standard Institution, London, BS EN 12697-35

11. BSI (2003) Bituminous mixtures-test method for hot mix asphalt: Specimen prepared by roller compactor, British Standard Institution, London, BS EN 12697-33
12. Ogundipe OM (2011) Mechanical Behaviour of Stress Absorbing Membrane Interlayers. University of Nottingham, Nottingham.

13. Molenaar AAA, Heerkens JCP, Verhoeven JMH, (1986). Effects of stress absorbing membrane interlayers, Association of Asphalt Paving Technologists. 